NASA TECHNICAL NOTE

J
0
$\vdots$
$\vdots$
$z$
$\vdots$
$\vdots$
$\vdots$
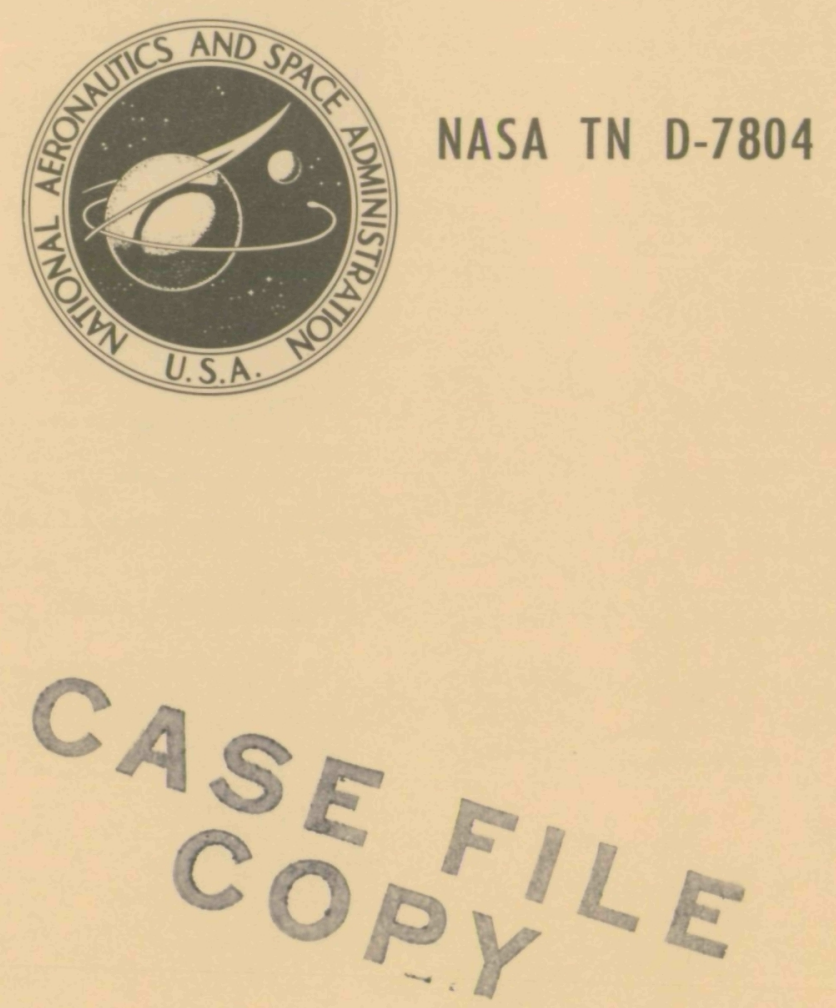

FERROGRAPHIC ANALYSIS OF WEAR DEBRIS FROM BOUNDARY LUBRICATION EXPERIMENTS WITH A FIVE-RING POLYPHENYL ETHER

by William R. Jones, Jr.

Lewis Research Center Cleveland, Obio 44135

NATIONAL AERONAUTICS AND SPACE ADMINISTRATION - WASHINGTON, D. C. • OCTOBER 1974 


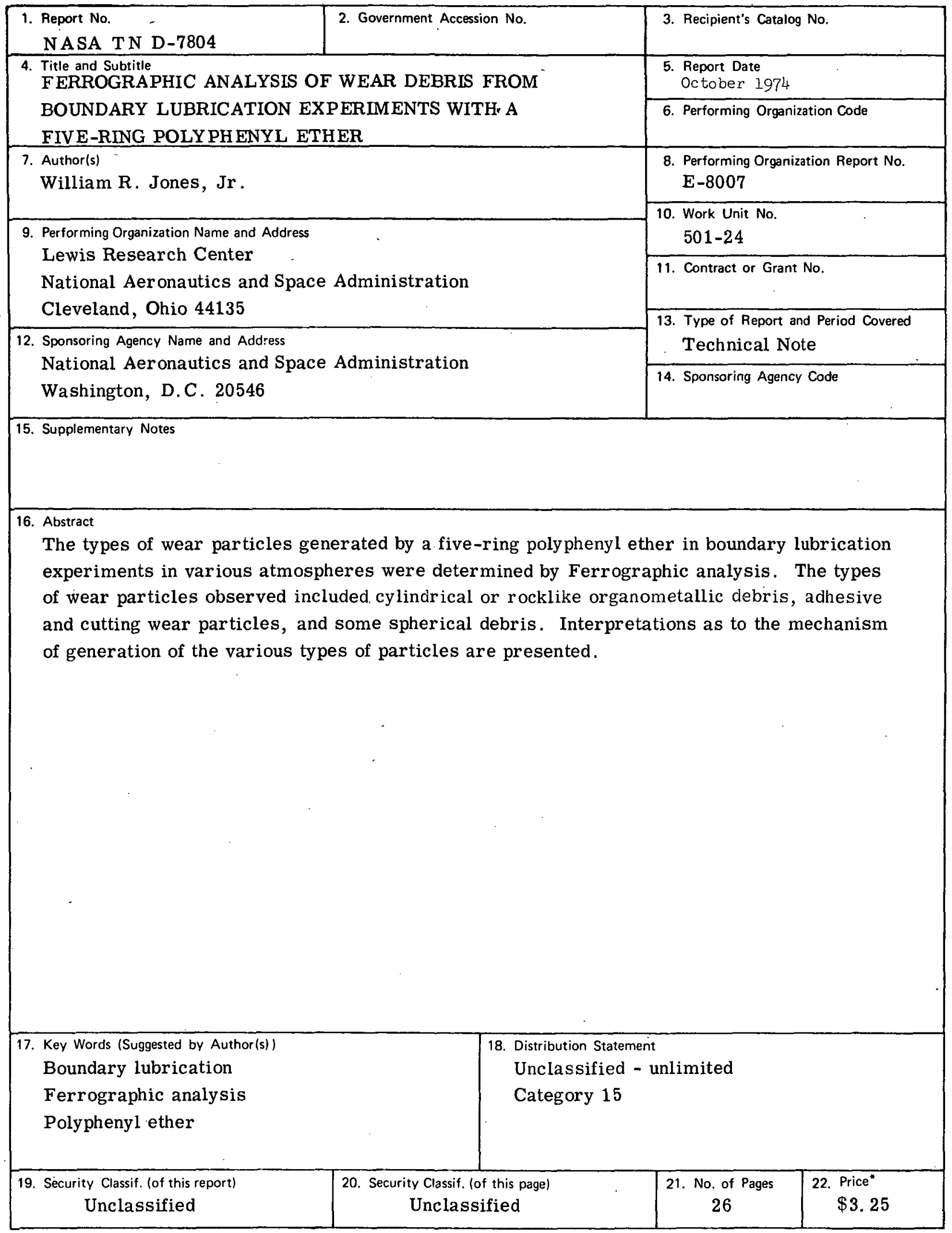

${ }^{-*}$ For sale by the National Technical Information Service, Springfield, Virginia 22151 


\title{
FERROGRAPHIC ANALYSIS OF WEAR DEBRIS FROM BOUNDARY LUBRICATION EXPERIMENTS WITH A FIVE-RING POLYPHENYL ETHER
}

\author{
by William R. Jones, Jr.
}

\author{
Lewis Research Center
}

\section{SUMMARY}

The types of wear particles generated by a five-ring polyphenyl ether in boundary lubrication experiments were determined by Ferrographic analysis. Lubricant samples were obtained from tests conducted on a ball-on-disk sliding friction apparatus. Conditions included a 1-kilogram load, a 17-meter-per-minute sliding speed, $100^{\circ}$ to $250^{\circ} \mathrm{C}$ disk temperatures, test atmospheres of air and nitrogen of varying moisture contents, and a test duration of 25 minutes. Test specimens were consumable electrode vacuum melted (CVM) M-50 steel.

In dry nitrogen (where high wear occurred) large quantities of an organometallic carbonaceous wear debris were observed; this debris consisted of either cylindrical or rocklike particles. The amount of the debris increased with increasing test temperature. In dry air (where lower wear occurred) smaller amounts of the carbonaceous debris were observed.

In wet atmospheres (air and nitrogen, where the lowest wear occurred) very little carbonaceous debris was generated. However, under these conditions, some spherical and a few severe (large) wear particles were observed.

Adhesive and cutting wear debris were observed under all conditions. However, the cutting debris appeared to be more prevalent in wet atmospheres (particularly wet air).

Therefore, it appears that a corrosive wear mechanism is operative with the polyphenyl ether under dry inert conditions. The presence of moisture (and to a lesser extent oxygen) inhibits this corrosive action. These observations are in accord with the radical anion wear model proposed by Goldblatt for polynuclear aromatics.

\section{INTRODUCTION}

The detection and analysis of wear debris generated in lubrication systems plays 
an important role in elucidating what wear mechanisms are occurring. In addition, the sudden appearance of or an increase in the rate of production of a particular type of wear particle may be related to the incipient failure of a system component.

There are a number of methods available for detecting and analyzing wear debris in lubricants. The quantity and size distribution of particles may be measured by using ordinary particle counters which are based on a variety of different principles (refs. 1 and 2). Atomic absorption, emission spectroscopy, and X-ray fluorescence are also commonly used techniques for elemental analysis (refs. 3 to 6). Debris may be collected by filtration, examined microscopically, and subjected to other analytical procedures such as X-ray diffraction (ref. 7) and neutron activation analysis (ref. 8).

However, each of these methods has certain deficiencies. Particle counters are not able to differentiate between metallic and organic debris. Nor do they provide any information concerning particle morphology. Filtration often results in a massive pileup of all particulates (including those unrelated to the wear process) on the filter. Thus, it is very difficult to study individual particles. The spectroscopic and irradiation techniques are extremely sensitive but again do not differentiate between particles of different chemical nature.

Recently, a new instrument, the Ferrograph, has been developed which is capable of precipitating magnetic particles from a lubricant onto a transparent substrate to yield a Ferrogram (ref. 9). The precipitated particles range in size from approximately 0.02 to a few micrometers and are arranged according to size on the substrate. The density of the deposit may be measured optically, and individual particles may be observed with a unique bichromatic microscope, the Ferroscope. The Ferrogram may also be examined with an electron microscope.

Polyphenyl ethers are among the most thermally stable organic fluids known. Therefore, they have often been considered as possible high-temperature lubricants (refs. 10 and 11). However, these ethers have exhibited poor boundary lubricating characteristics in friction and wear tests (refs. 12 to 14), pump loops (ref. 15), and bearing tests (ref. 16). They are particularly poor lubricants under dry inert conditions (refs. 12, 15, and 17).

The objectives of this investigation were (1) to determine types of wear particles generated by a five-ring polyphenyl ether in boundary lubrication experiments by using Ferrographic analysis and (2) to relate the particle types to the wear mechanisms occurring with this fluid.

Lubricant samples were obtained from friction and wear tests conducted on a ballon-disk sliding friction apparatus. Conditions included a 1-kilogram load (initial Hertz stress, $\left.10^{9} \mathrm{~N} / \mathrm{m}^{2}\right)$, a 17 -meter-per-minute $(100-\mathrm{rpm})$ sliding speed, $100^{\circ}$ to $250^{\circ} \mathrm{C}$ disk temperatures, test atmospheres of air and nitrogen of varying moisture contents, and a test duration of 25 minutes (in most cases). Test specimens were consumable 
electrode vacuum melted (CVM) M-50 steel.

\section{APPARATUS}

The ball-on-disk sliding friction apparatus is shown in figure 1. The test specimens were placed in a stainless steel chamber. The atmosphere was controlled with respect to oxygen and moisture content. A stationary 0.476 -centimeter-radius ball was placed in sliding contact with a rotating 6.3-centimeter-diameter disk. A sliding speed of 17 meters per minute $(100 \mathrm{rpm})$ was maintained. A normal load of 1 kilogram (initial Hertz stress, $1 \times 10^{9} \mathrm{~N} / \mathrm{m}^{2}$ ) was applied with a deadweight. Balls and disks were made of CVM M-50 tool steel. Disk and ball Rockwell hardness was C-62 to C-64.

The disk was partially submerged in a polyimide cup containing the test lubricant and was heated by induction. Bulk lubricant temperature was measured with a thermocouple. Disk temperature was monitored with an infrared pyrometer. Friction force was measured with a strain gage and was recorded on a strip-chart recorder.

\section{PROCEDURE}

Disks were ground and lapped to a root-mean-square surface finish of $10 \times 10^{-8}$ to $20 \times 10^{-8}$ meter ( 4 to $8 \mu$ in.) and balls to $2.5 \times 10^{-8}$ meter $(1 \mu$ in.). Specimens were scrubbed with a paste of levigated alumina and water, rinsed with tap water and distilled water, and then placed in a desiccator.

All lubricants tested under dry conditions were degassed at approximately $150^{\circ} \mathrm{C}$ $\left(302^{\circ} \mathrm{F}\right)$ at 2 torr for 1 hour. The Karl Fischer method indicated that this degassing procedure reduces dissolved water content in the test fluids to less than $20 \mathrm{ppm}$.

The specimens were assembled, and $3 \times 10^{-5}$ cubic meter $(30 \mathrm{ml})$ of lubricant was placed in the lubricant cup. The test chamber (volume, $3.7 \times 10^{-3} \mathrm{~m}^{3}$ (3. 7 liters)) was purged with the test atmosphere for 10 minutes at a flow rate in excess of $5 \times 10^{-2}$ cubic meter per hour ( 50 liters $/ \mathrm{hr}$ ). The disk was heated by induction to the test temperature while rotating. The ball was then loaded against the disk. The test atmosphere flow rate was reduced to $3.5 \times 10^{-2}$ cubic meter per hour ( 35 liters $/ \mathrm{hr}$ ), and a $6.9 \times 10^{-3}$-newton-per-square-meter (1-psig) pressure was maintained in the chamber . The lubricant was heated only by heat transfer from the rotating disk. The bulk lubricant temperature was essentially the same as the disk temperature at disk temperatures to $100^{\circ} \mathrm{C}\left(212^{\circ} \mathrm{F}\right)$. At disk temperatures of $200^{\circ}$ and $300^{\circ} \mathrm{C}\left(392^{\circ}\right.$ and $\left.572^{\circ} \mathrm{F}\right)$, the bulk oil temperatures stabilized at approximately $150^{\circ}$ and $200^{\circ} \mathrm{C}\left(302^{\circ}\right.$ and $\left.392^{\circ} \mathrm{F}\right)$, respectively.

Friction force and bulk lubricant temperature were continuously recorded. Disk temperature was continuously monitored. Experiments were terminated after 
25 minutes (in most cases) and rider wear scar diameter was recorded. All the used lubricant was retained for Ferrographic analysis.

Because of the extreme sensitivity of the Ferrographic technique, a rigorous cleaning procedure was adopted. All parts of the test apparatus that came into contact with the test lubricant were cleaned with a dilute acid solution. This acid solution was prepared by adding 10 drops of concentrated nitric acid and 10 drops of concentrated hydrochloric acid to $5 \times 10^{-5}$ cubic meter $(50 \mathrm{ml})$ of distilled water. This solution dissolved any metallic debris left from the previous test. In addition, the solvents and the unused oil were subjected to Ferrographic analysis to determine if they were free of metallic debris. Essentially no metallic contamination was found in these fluids.

\section{TEST ATMOSPHERES}

Four test atmospheres were used in this study. They were wet and dry air and wet and dry nitrogen. Dry air and dry nitrogen contained less than 50 and $20 \mathrm{ppm}$ of moisture, respectively. Both wet gases had a relative humidity of greater than 95 percent at $25^{\circ} \mathrm{C}$.

Relative humidity of the wet gases was monitored with an electronic hygrometer accurate to \pm 4 percent. The moisture content of the dry gases was monitored by a moisture analyzer with an accuracy of $\pm 10 \mathrm{ppm}$. A wet gas was obtained by bubbling the dry gas through a water reservoir.

\section{EXPERIMENTAL LUBRICANT}

The polyphenyl ether used in these studies was an isomeric mixture of five-ring components. This fluid contained no additives. Typical properties of this fluid appear in table I. Previously reported wear results (ref. 17) for this fluid in dry air and dry nitrogen appear in figure 2(a). Figure 2(b) illustrates the effect of moisture on wear rate (ref. 12).

\section{RESULTS}

Several different types of wear debris were observed when the oil samples from the friction and wear tests were subjected to Ferrographic analysis. Table II summarizes the types of wear debris observed in this study. In addition, table II contains information regarding the morphology, size range, and appearance in the bichromatic microscope. 


\section{Wear Results}

Figure 2(a) gives rider wear for the polyphenyl ether as a function of disk temperature for atmospheres of dry air and dry nitrogen. The effect of moisture on rider wear is shown in figure $2(\mathrm{~b})$ at three disk temperatures: $150^{\circ}, 250^{\circ}$, and $350^{\circ} \mathrm{C}$. It should be noted that the wear rates in the dry atmospheres of figure 2(b) do not exactly correspond to the rates shown in figure 2(a). The discrepancies arise because these results are from two separate studies and the wear rates were based on different test durations ( $25 \mathrm{~min}$ and $1 \mathrm{hr}$ ). In addition, the relative humidity of the wet gases in the study of figure 2(b) was 50 percent compared with greater than 95 percent in the present study. Nevertheless, the figures are qualitatively consistent and do illustrate the following points: High wear occurs under dry inert conditions. The presence of either oxygen or moisture in the test atmosphere reduces wear, with moisture having the greater effect. The abnormally low wear at $25^{\circ} \mathrm{C}$ in figure $2(\mathrm{a})$ is due to the generation of an elastohydrodynamic film.

\section{Ferrogram Results}

Particles in the used oil are precipitated according to size on a transparent substrate, and the result is called a Ferrogram. The largest and the greatest density of wear particles occurs at the end of the Ferrogram where the used oil first contacts the substrate. For comparison purposes all photomicrographs were taken in this region.

The bichromatic (red-green) system of the Ferroscope facilitates differentiation among the types of wear debris. Free metal appears bright red, nonmetallic translucent particles appear yellow or green, and nonmetallic opaque debris appears black or dark red.

A typical photomicrograph from a Ferrogram appears in figure 3. At least three particle types are discernible. First, the horizontal red strings of material are adhesive wear particles. Second, the green material which appears in islands or randomly oriented strings is oxides. Third, the large black rocklike particles are carbonaceous debris. It should be noted that the term carbonaceous is used in this report in a descriptive rather than a chemical sense.

\section{Effect of Temperature}

Figure 4 illustrates the effect of disk temperature on the generation of wear debris in dry nitrogen. Some adhesive and cutting debris are evident. However, the most important observation is the large amount of carbonaceous debris present. Note the 
large increase in this type of debris at $250^{\circ}$. C. There also appears to be two distinct types. Some particles are irregularly shaped and rocklike. Others appear as small cylinders which are typically 1 to 3 micrometers in diameter and 10 to 15 micrometers in length. In general, the rocklike particles decrease and the cylinders increase with increasing temperature. The cylinders also decrease in size with increasing temperature.

\section{Effect of Oxygen and Moisture}

The effect of oxygen or moisture in the test atmosphere on wear debris generation at $100^{\circ} \mathrm{C}$ is illustrated in figure 5 . It is immediately evident that the presence of moisture in the test atmosphere almost completely inhibits the formation of the carbonaceous debris. The presence of oxygen also decreases the production of carbonaceous debris, but to a much lesser extent than moisture. More metallic debris is noted in wet air than in wet nitrogen.

Cutting wear debris was observed in all Ferrograms but was more prevalent under moist conditions, particularly in wet air. Some examples of this type of debris appear in figure 6.

Another moisture effect manifests itself in the generation of spherical debris such as that illustrated in figure 7 . Spheres were rarely observed in dry atmospheres but always under moist conditions.

Finally, a number of Ferrograms contained some severe (large) wear particles, such as the large wear fragment shown in figure 8. Again, these particles appeared more frequently in moist atmospheres.

\section{DISCUSSION}

The boundary lubrication behavior of polyphenyl ethers has been well documented. Polyphenyl ethers are poor boundary lubricants under dry inert conditions (refs. 12, 15, and 17). Under these conditions they also form large quantities of an insoluble carbonaceous debris (refs. 8, 12,13,15, and 18). The presence of either oxygen or moisture in the test atmosphere improves their boundary lubricating properties. Moisture, and to a lesser extent oxygen, reduces the production of the carbonaceous debris.

Polyphenyl ethers have also performed poorly in bearing tests (ref. 16). This is surprising. The aromatic structure of these fluids yields a high pressure-viscosity coefficient, which, combined with their high bulk viscosity, should make these fluids excellent elastohydrodynamic (EHD) film formers. Their poor bearing performance 
may be related to their poor boundary characteristics. Polyphenyl ethers also exhibit poor wettability (ref. 12). Poor wetting can encourage lubricant starvation in the vicinity of the inlet to the Hertzian contact, which would lead to thinner than expected EHD films.

At any rate, the polyphenyl ethers appear to follow the general boundary lubrica ting behavior of polynuclear aromatics reported by Appeldoorn and Tao (ref. 19). The following sections discuss the various types of wear debris generated by the polyphenyl ether during the boundary lubrication experiments.

\section{Carbonaceous Debris}

Many investigators have observed the generation of carbonaceous debris in boundary lubrication experiments with polyphenyl ethers. Apparently, a wearing situation must exist for its production, since this type of debris is not observed in static thermal stability tests. Spar and Damasco (ref. 13) found large quantities of metallic debris in the carbonaceous product from their experiments. Analysis of the organic portion of their debris yielded a higher molecular weight structure similar to the base fluid. Analysis of the carbonaceous debris in the study of reference 18 yielded similar results. Therefore, this debris is not just a cokelike deposit caused by high-temperature degradation of the lubricant.

Goldblatt (ref. 20) proposed the following model to explain the lubricating behavior of aromatics: He theorized that aromatic radical anions are generated at the wearing surfaces. These highly reactive molecules can then react with the metal surfaces and produce a form of corrosive wear. The radical anions can also be "quenched" by reacting with either oxygen or water and are thus prevented from corrosively attacking the surface.

One may speculate that a similar phenomenon occurs with the polyphenyl ethers. In dry nitrogen, radical anions formed from the polyphenyl ether molecules attack the metal surface and produce an organometallic friction polymer (called surface resin by Goldblatt). This product is removed from the surface during the sliding process and accumulates around the wear scar and in the fluid. The fact that much of the observed carbonaceous debris is in the form of small cylinders tends to support this idea. Other investigators, such as Antler (ref. 21) and May, Morris, and Atack (ref. 22), have reported the production of roller-shaped debris in sliding experiments.

Another interesting observation is that, even though the wear (determined by the wear scar) is high in dry nitrogen, very little free metallic debris is evident in the Ferrograms. If a corrosive mechanism is operative, one would expect much of the worn metal to be contained in the carbonaceous debris in the form of an organometallic 
reaction product. Of course, it would also be possible for free metallic particles to become embedded in the carbonaceous debris while it is being stripped off the surface. At any rate, when a Ferrogram containing carbonaceous debris is placed on a hotplate at $480^{\circ} \mathrm{C}$, the debris becomes translucent and retains its original morphology. It also exhibits the orange-red color of iron oxide. The fact that large quantities of this carbonaceous debris are precipitated by the magnetic field of the Ferrograph further indicates the presence of iron. An electron micrograph of some of the carbonaceous particles appears in figure 9(a). An iron X-ray map of the same area appears in figure $9(\mathrm{~b})$ and confirms the presence of iron in both types of particle.

The large decrease in wear rate at temperatures above $200^{\circ} \mathrm{C}$ (in dry nitrogen) may be a consequence of the increased reactivity of the radical anions at high temperature. If the rate of production of surface resin were greater than its effective removal rate during the sliding process, a reduction in wear could be effected. This would be a result of a quasi-hydrodynamic film formation or a microelastohydrodynamic effect such as proposed by Fein and Kreuz (refs. 7 and 23).

The decrease in carbonaceous debris in the presence of water or oxygen follows the Goldblatt model. Either water or oxygen "quenches" or ties up radical anions before they can react with the surface. The apparent greater effectiveness of water compared with oxygen in quenching the anions may be a concentration effect. The high solubility parameter of polyphenyl ethers indicates a high solubility for water but a low solubility for the fixed gases, such as oxygen (ref. 24).

\section{Adhesive Wear Debris}

The generation of wear particles by an adhesion mechanism has been proposed by many investigators (refs. 25 to 27). This mechanism is operative when the boundary film fails and metal-to-metal junctions are formed. Relative motion then causes the welded junction to shear. Material is transferred from one surface to another and is subsequently removed during the sliding process.

Suh (ref. 28) has proposed a new wear mechanism based on dislocation theory. It involves the formation of subsurface voids, crack propagation between the voids, and the subsequent shearing of this material to form a sheetlike wear particle. This sheetlike particle may then be broken into smaller particles or may be rolled into a larger particle during the sliding process. Many of the particles observed in this study which have been referred to as adhesive wear do appear as sheets.

Figure 10 is a photomicrograph of a portion of a wear scar from one of the experiments in this study. It was taken with the Ferroscope by utilizing an interference contrast technique. It appears that a thin layer of material was generated on the surface. This layer may have been related to the often mentioned but little understood 
white or nonetching wear transformation layer (refs. 29 to 31) and may have been the source of so-called adhesive wear particles. In fact, there is an area in the center of the photograph where some of this layer was stripped off. The vertical resolution in this photograph is about $5 \times 10^{-8}$ meter $(500 \AA)$.

\section{Cutting Wear Debris}

Another common wear mode is cutting (ref. 32). This type of wear results when a hard particle or surface plows out a softer surface. It is also often referred to as abrasive wear. Loose work-hardened wear particles are no doubt present in the fluid during the test. However, Scott, Seifert, and Westcott (ref. 33) have been unable to reproduce cutting wear particles by adding abrasive particles (sand) to lubricants. A possible explanation for this type of debris could be a micromachining process caused by work-hardened particles adhering to the rider prow. Another possibility may be hard inclusions in the metal itself, such as carbides. The increased generation of cutting wear particles in wet atmospheres may have been caused by the formation of abrasive oxides under these conditions.

\section{Spherical Debris}

Many investigators have noted the occurrence of spherical particles in bearing and friction and wear tests (refs. 34 to 40). Finken (ref. 34) reported the formation of large spheres (apparently iron oxide) in friction and wear tests with 1020 steel. Suh (ref. 28) observed spherical metallic debris and theorized that it was produced from metal particles which were trapped between the sliding surfaces and rolled into a ball. Spheres have also been observed in fretting studies (ref. 38). Broszeit and Hess (ref. 39) observed spheres in grinding debris and related their formation to a hightemperature melting process. Scott and Mills (refs. 36 and 37) observed metallic spheres during microscopic examination of bearing fatigue surfaces. They felt that the spheres are formed by a deformation process within propagating fatigue cracks. In fact, it has been suggested that their detection in a bearing lubricant may allow the prediction of incipient bearing fatigue failure (ref. 33).

The spheres observed in this study appeared as free metal in the bichromatic system (i.e., they appeared red). Energy-dispersion X-ray analysis confirmed their metallic content. These spheres may have been generated by a fatigue related process. Certainly, fatigue under sliding conditions has been demonstrated by a number of investigators (refs. 41 to 43 ). However, the number of stress cycles generated in the wear tests of this study was very low (generally less than 2500). And it is possible 
that the disk surface was worn away before crack propagation could occur. Nevertheless, spheres were always observed under moist test conditions and rarely in dry atmospheres. The presence of moisture certainly accelerates the fatigue process (refs. 44 and 45). An electron micrograph of some typical spheres appears in figure 11(a).

\section{Severe (Large) Wear Particles}

Occasionally some severe (large) wear particles (diam, $>30 \mu \mathrm{m}$ ) were observed in the Ferrograms. These particles may have been the result of processes such as surface fatigue or surface fracture. However, they were only rarely encountered and did not appear to be a major component in the wear processes of this study. An electron micrograph of one such particle appears in figure 11(b).

\section{SUMMARY OF RESULTS}

The major results of the Ferrographic analysis of the wear debris generated by a five-ring polyphenyl ether in boundary lubrication experiments may be summarized as follows:

1. In dry nitrogen (where high wear occurred) large quantities of carbonaceous organometallic wear debris were observed; this debris consisted of either cylindrical or rocklike particles. The amount of the debris increased with increasing test temperature.

2. In dry air (where lower wear occurred) smaller amounts of the carbonaceous debris were observed.

3. In wet atmospheres (air and nitrogen, where the lowest wear occurred) very little carbonaceous debris was generated. However, under these conditions, some spherical and a few severe (large) wear particles were observed.

4. Adhesive and cutting wear debris were observed under all conditions. However, the cutting debris appeared to be more prevalent in wet atmospheres (particularly wet air).

5. Therefore, it appears that a corrosive wear mechanism is operative with the polyphenyl ether under dry inert conditions. The presence of moisture (and to a lesser 
extent oxygen) inhibits this corrosive action. These observations are in accord with the radical anion wear model proposed by Goldblatt for polynuclear aromatics.

Lewis Research Center,

National Aeronautics and Space Administration,

Cleveland, Ohio, July 30, 1974,

501-24.

\section{REFERENCES}

1. Davis, R.: Rapid Response Instrumentation for Particle Size Analyses. A Review, Part One. Amer. Lab., vol. 5, no. 12, Dec. 1973, pp. 17-23.

2. Davis, R.: Rapid Response Instrumentation for Particle Size Analyses. A Review, Part Two. Amer. Lab., vol. 6, no. 1, Jan. 1974, pp. 73-86.

3. Berg, J. L.; and Lieser, J. E.: Lubricant Testing as an Aid to Bearing Damage Analysis. Lub. Engr., vol. 29, no. 12, Dec. 1973, pp. 539-545.

4. Burrows, J. A.; Herdt, J. C.; and Willis, J. B.: Determination of Wear Metals in Used Lubricating Oils by Atomic Absorption Spectrometry . Analyt. Chem., vol. 37, no. 4, April 1965, pp. 579-582.

5. Kittinger, Donald C.; and Bond, Allan.: Spectrometric Analysis to Determine Wear Metal in Engine Lubricating Oil. In: Proc. 18th Ann. Nat. Aerospace Electronics Conf., May 16-18, 1966, Dayton, Ohio, pp. 251-256.

6. Jackson, Donald R.: Comparison of Atomic Absorption and Emission Spectroscopy in the Evaluation of Lubrication in Normally-Operating Diesel Engines. Lub. Engr., vol. 28, no. 3, Mar. 1972, pp. 76-81.

7. Fein, R. S.; and Kreuz, K. L.: Chemistry of Boundary Lubrication of Steel by Hydrocarbons. ASLE Trans., vol. 8, no. 1, Jan. 1965, pp. 29-38.

8. Klaus, E. E.; Fenske, M. R.; and Tewksbury, E. J.: Fluids, Lubricants, Fuels and Related Materials. AFML-TR-67-107, Part II, Air Force Materials Lab. (AD-837221), 1968.

9. Seifert, W. W. ; and Westcott, V. C.: A Method for the Study of Wear Particles in Lubricating Oil. Wear, vol. 21, 1972, pp. 27-42.

10. Gunderson, Reigh C.; and Hart, Andrew W., eds.: Synthetic Lubricants. Reinhold Publ. Corp., 1962.

11. Mahoney, C. L.; Barnum, E. R.; Kerlin, W. W.; and Sax, K. J.: Meta-Linked Polyphenyl Ethers as High-Temperature Radiation-Resistant Lubricants. ASLE Trans., vol. 3, no. 1, April 1960, pp. 83-92 
12. Jones, William R., Jr.; and Hady, William F.: Effect of Humidity and a Wettability Additive on Polyphenyl Ether Boundary Lubrication of Steel in Air and Nitrogen to $350^{\circ} \mathrm{C}$. NASA TN D-6055, 1970.

13. Spar, Charles; and Damasco, Frank: High-Temperature Fluid Lubrication. ASLE Trans., vol. 7, no. 2, April 1964, pp. 211-217.

14. Montgomery, R. S.: Lubrication of Bearing Aluminum With Polyphenyl Ethers. Wear, vol. 14, 1969, pp. 213-217.

15. Jones, William R., Jr.; Hady, William F.; and Swikert, Max A.: Lubrication With Some Polyphenyl Ethers and Superrefined Mineral Oils in a $600^{\circ} \mathrm{F}\left(316^{\circ} \mathrm{C}\right)$ Inerted Vane Pump Loop. NASA TN D-5096, 1969.

16. Bamberger, E. N.; Zaretsky, E. V.; and Anderson, W. J.: Effect of Three Advanced Lubricants on High-Temperature Bearing Life. J. Lubr. Tech., vol. 92 , no. 1, Jan. 1970 , pp. 23-33.

17. Jones, William R., Jr.: Effect of Oxygen Concentration on Boundary Lubricating Characteristics of an Unformulated C-Ether to $300^{\circ} \mathrm{C}$. NASA TN D-7155, 1973.

18. Loomis, W. R.: Evaluation of Five Bearing-Separator Materials and Polyphenyl Ether Lubricants for Use in Space Power Generation Systems. NASA TN D-2663, 1965.

19. Appeldoorn, J. K.; and Tao, F. F.: The Lubricity Characteristics of Heavy Aromatics. Wear, vol. 12, no. 2, 1968, pp. 117-130.

20. Goldblatt, I. L.: Model for Lubrication Behavior of Polynuclear Aromatics. Ind. Engr. Chem. Prod. Res. Develop., vol. 10, no. 3, Sept. 1971, pp. 270-278.

21. Antler, Morton: Wear, Friction, and Electrical Noise Phenomena in Severe Sliding System. ASLE Trans., vol. 5, no. 2, Nov. 1962, pp. 297-307.

22. May, W. D.; Morris, E. L.; and Atack, D.: Dynamics of a Visco-elastic Wear Particle Between Sliding Surfaces. J. Appl. Phys., vol. 34, no. 7, Jul. 1963, pp. 1920-1928.

23. Fein, R. S.: Discussion to a Thermal Elastohydrodynamic Theory for Individual Asperity-Asperity Collisions by P. E. Fowles. J. Lubr. Tech., July 1971, pp. 395-396.

24. Beerbower, A.: Environmental Capability of Liquid Lubricants. Interdisciplinary Approach to Liquid Lubricant Technology. NASA SP-318, 1972, pp. 365-431.

25. Bowden, Frank P.; and Tabor, D.: The Friction and Lubrication of Solids I. Oxford University Press, 1950. 
26. Archard, J. F.; and Hirst, W.: The Wear of Metals Under Unlubricated Conditions. Proc. Roy. Soc. (London), vol. 236A, 1956, pp. 397-410.

27. Finkin, Eugene F.: Speculations on the Theory of Adhesive Wear. Wear, vol. 21, 1972, pp. 103-114.

28. Suh, Nam P.: The Delamination Theory of Wear. Wear, vol. 25, 1973, pp. 111124.

29. Eyre, T. S.; and Baxter, A.: The Formation of White Layers at Rubbing Surfaces. Tribology, vol. 5, no. 6, Dec. 1972, pp. 256-261.

30. Eyre, T. S.; and Maynard, D.: Surface Aspects of Unlubricated Metal-to-Metal Wear. Wear, vol. 18, 1971, pp. 301-310.

31. Montgomery, R. S.: Run-In and Glaze Formation on Gray Cast Iron Surfaces. Wear, vol. 14, 1969, pp. 99-105.

32. Burwell, John T., Jr.: Survey of Possible Wear Mechanisms. Wear, vol. 1, 1957, pp. 119-141.

33. Scott, D.; Seifert, W. W.; and Westcott, V. C.: The Particles of Wear. Sci. Am., vol. 230, no. 5, May 1974, pp. 88-97.

34. Finken, Eugene: Surface Roughness in Wear. Wear, vol. 6, 1963, pp. 293-302.

35. Loy, B.; and McCallum, R.: Mode of Formation of Spherical Particles in Rolling Contact Fatigue. Wear, vol. 24, 1973, pp. 219-228.

36. Scott, D.; and Mills, G. H.: Spherical Debris - Its Occurrence, Formation and Significance in Rolling Contact Fatigue. Wear, vol. 24, 1973, pp. 235-242.

37. Scott, D.; and Mills, G. H.: A Scanning Electron Microscope Study of Fracture Phenomena Associated With Rolling Contact Surface Fatigue Failure. Wear, vol. 16, 1970, pp. 234-237.

38. Stowers, I. F.; and Rabinowicz, E.: Spherical Particles Formed in the Fretting of Silver. J. Appl. Phys., vol. 43, no. 5, May 1972, pp. 2485-87.

39. Broszeit, E.; and Hess, F. J.: Discussion to "A Scanning Electron Microscope Study of Fracture Phenomena Associated With Rolling Contact Fatigue Failure". Wear, vol. 17, 1971, pp. 314-315.

40. Cummins, R. A.; Doyle, E. D.; and Rebecchi, B.: Wear Damage to Spur Gears. Wear, vol. 27, 1974, pp. 115-120.

41. Bayer, R. D.; and Schumacher, R. A.: On the Significance of Surface Fatigue in Sliding Wear. Wear, vol. 12, 1968, pp. 173-183. 
42. Goldblatt, Irwin L.: Surface Fatigue Initiated by Fatty Acids. ASLE Trans., vol. 16, no. 2, April 1973, pp. 150-159.

43. Kolozsvary, Z.: The Study of Surface Fatigue in Sliding Wear. Wear, vol. 25, 1973, pp. 215-224.

44. Schatzberg, P.; and Felsen, I. M.: Effects of Water and Oxygen During Rolling Contact Lubrication. Wear, vol. 12, 1968, pp. 331-342.

45. Riddei, V.; Pacor, P.; and Appeldoorn, J. K.: Cavitation Erosion and Rolling Contact Fatigue. Wear, vol. 27, 1974, pp. 99-108. 
TABLE I. - SOME PROPERTIES OF A FIVE-RING

\section{POLYPHENYL ETHER}

\begin{tabular}{|c|c|}
\hline \multicolumn{2}{|l|}{ Kinematic viscosity $\mathrm{m}^{2} / \mathrm{sec}(\mathrm{cS})$} \\
\hline At $38^{\circ} \mathrm{C}\left(100^{\circ} \mathrm{F}\right)$ & $3.6 \times 10^{-4}(360)$ \\
\hline At $99^{\circ} \mathrm{C}\left(210^{\circ} \mathrm{F}\right)$ & $1.3 \times 10^{-5}(13)$ \\
\hline At $350^{\circ} \mathrm{C}\left(662^{\circ} \mathrm{F}\right)$ & $7.2 \times 10^{-7}(0.72)$ \\
\hline Pour point, ${ }^{\mathrm{o}} \mathrm{C}\left({ }^{\mathrm{O}} \mathrm{F}\right)$ & $5(40)$ \\
\hline Flash point, ${ }^{\mathrm{O}} \mathrm{C}\left({ }^{\mathrm{O}} \mathrm{F}\right)$ & $288(550)$ \\
\hline Fire point, ${ }^{\mathrm{O}} \mathrm{C}\left({ }^{\mathrm{O}} \mathrm{F}\right)$ & $350(662)$ \\
\hline Density at $38^{\circ} \mathrm{C}\left(100^{\circ} \mathrm{F}\right), \mathrm{kg} / \mathrm{m}^{3}(\mathrm{~g} / \mathrm{ml})$ & $1.19 \times 10^{3}(1.19)$ \\
\hline Thermal decomposition (isoteniscope), ${ }^{\mathrm{O}} \mathrm{C}\left({ }^{\mathrm{O}} \mathrm{F}\right)$ & $443(830)$ \\
\hline Vapor pressure at $343^{\circ} \mathrm{C}\left(650^{\circ} \mathrm{F}\right)$, torr & 12 \\
\hline Surface tension at $25^{\circ} \mathrm{C}\left(77^{\circ} \mathrm{F}\right), \mathrm{N} / \mathrm{cm}$ (dynes $\left./ \mathrm{cm}\right)$ & $5 \times 10^{-4}(50)$ \\
\hline
\end{tabular}

TABLE II. - DESCRIPTION OF DIFFERENT TYPES OF WEAR DEBRIS GENERATED BY

A FIVE-RING POLYPHENYL ETHER

\begin{tabular}{|c|c|c|c|}
\hline Type of wear debris & $\begin{array}{c}\text { Morphology (as debris appears } \\
\text { in Ferrograms) }\end{array}$ & $\begin{array}{l}\text { Size range, } \\
\qquad \mu \mathrm{m}\end{array}$ & $\begin{array}{l}\text { Appearance in } \\
\text { bichromatic } \\
\text { microscope }\end{array}$ \\
\hline \multicolumn{4}{|l|}{ Free metal } \\
\hline Adhesive & $\begin{array}{l}\text { Strings (actually made up of } \\
\text { small asymmetrical flakes) } \\
\text { which have agglomerated } \\
\text { during precipitation }\end{array}$ & Length, $<5$ & Bright red \\
\hline Cutting & $\begin{array}{l}\text { Individual particles (wire- } \\
\text { like turnings and crescent- } \\
\text { shaped chips) }\end{array}$ & Variable & Bright red \\
\hline Spheres & $\begin{array}{l}\text { Spherical particles (often } \\
\text { found interspersed in } \\
\text { adhesive strings) }\end{array}$ & Diameter, 1 to 10 & Bright red \\
\hline Severe wear & $\begin{array}{l}\text { Large irregularly shaped } \\
\text { fragments }\end{array}$ & Diameter, 30 to 50 & Bright red \\
\hline Inorganic (oxides) & $\begin{array}{l}\text { Translucent islands or } \\
\text { randomly oriented strings }\end{array}$ & Diameter, $<1$ & Yellow-green \\
\hline Organic & $\begin{array}{l}\text { Carbonaceous particles (con- } \\
\text { taining some metallic debris) } \\
\text { Rocklike } \\
\text { Cylindrical }\end{array}$ & $\begin{array}{l}\text { Diameter, } 5 \text { to } 20 \\
\text { Diameter, } 1 \text { to } 3 ; \\
\text { length, } 10 \text { to } 15\end{array}$ & Dark red \\
\hline
\end{tabular}




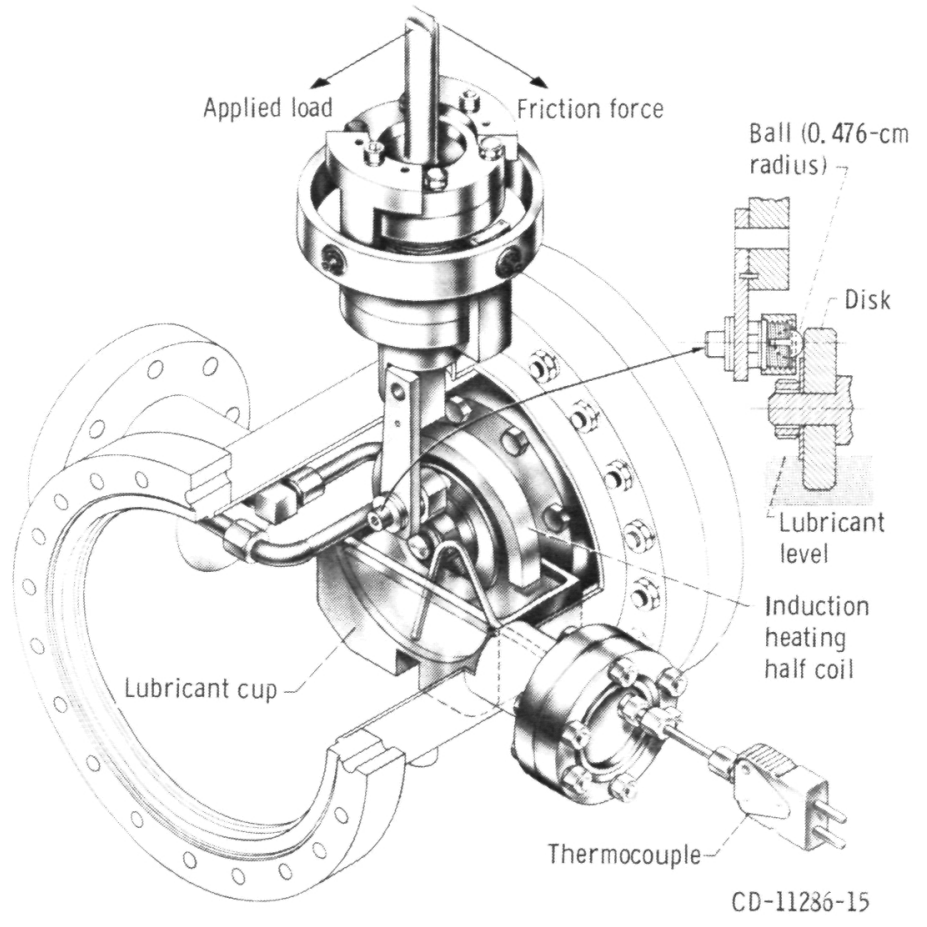

Figure 1. - Friction and wear apparatus. 


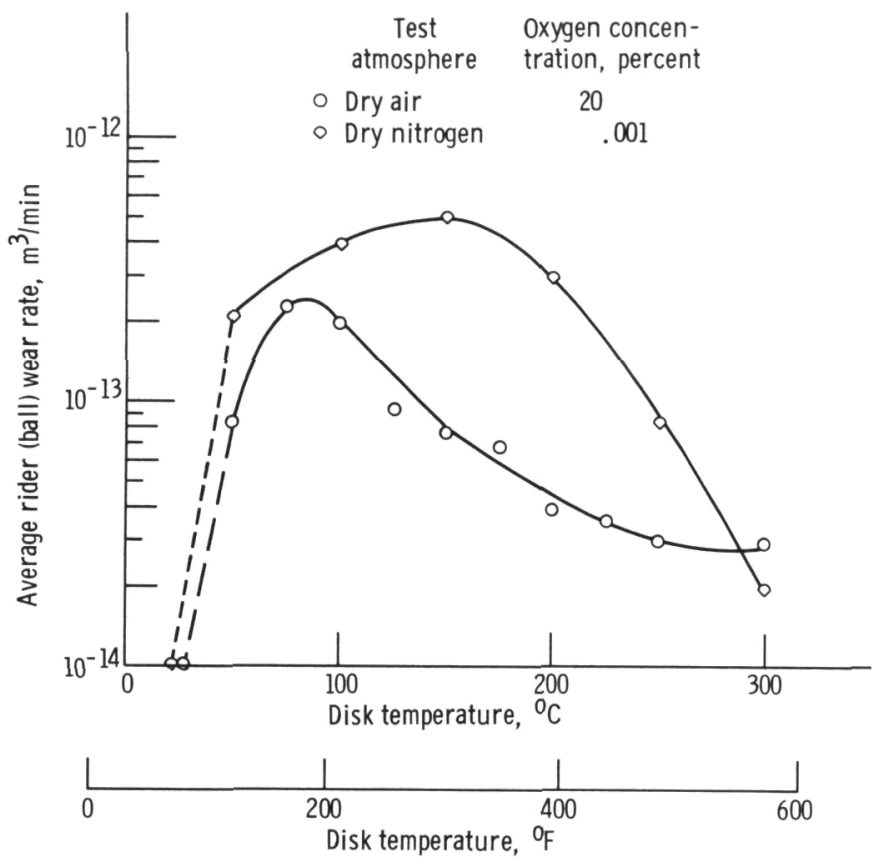

(a) Test duration, 25 minutes (from ref. 17).

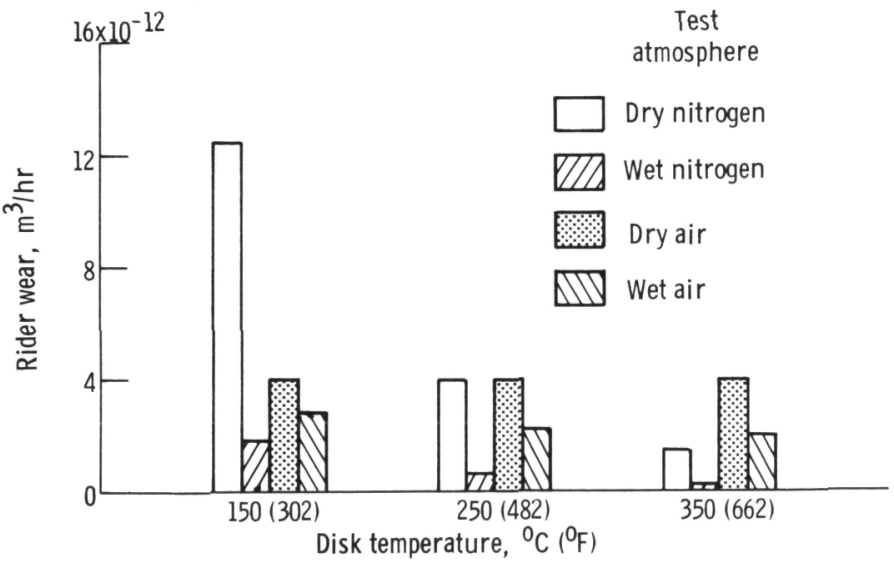

(b) Test duration, 1 hour (from ref. 12).

Figure 2. - Rider wear as function of disk temperature with five-ring polyphenyl ether as lubricant in various test atmospheres. Specimen material, CVM M-50 steel; load, I kilogram; sliding speed, 17 meters per minute $(100 \mathrm{rpm})$. 


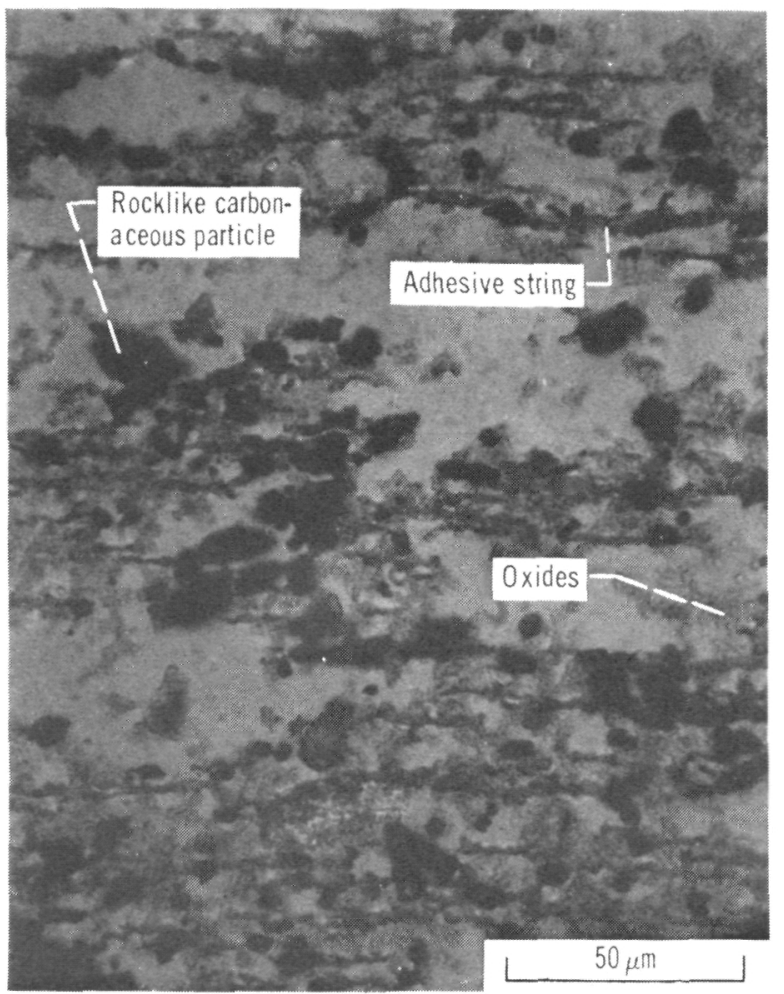

Figure 3. - Photomicrograph of wear debris generated by polyphenyl ether at $100^{\circ} \mathrm{C}$ in dry test atmosphere of 1 percent oxygen and 99 percent nitrogen (by volume). 


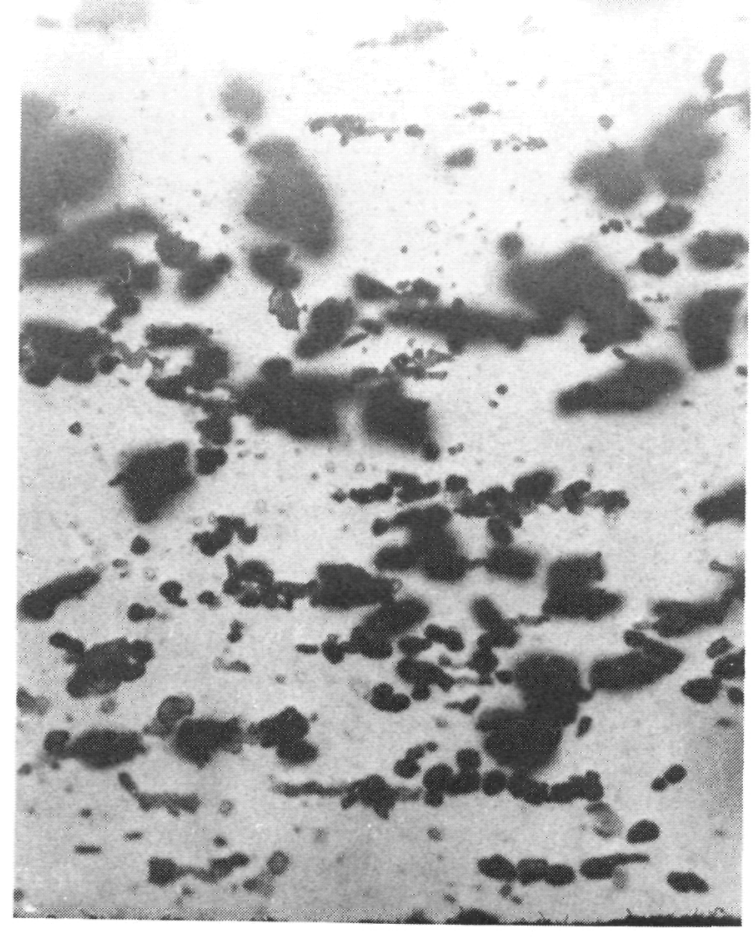

(a) $100^{\circ} \mathrm{C}$.

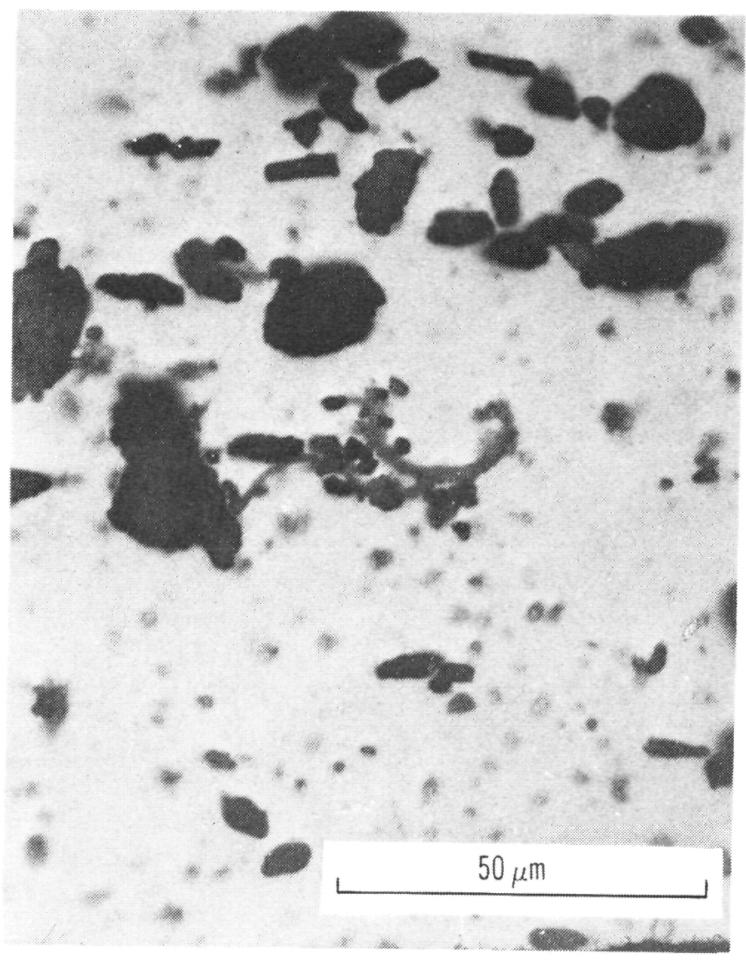

(b) $150^{\circ} \mathrm{C}$.

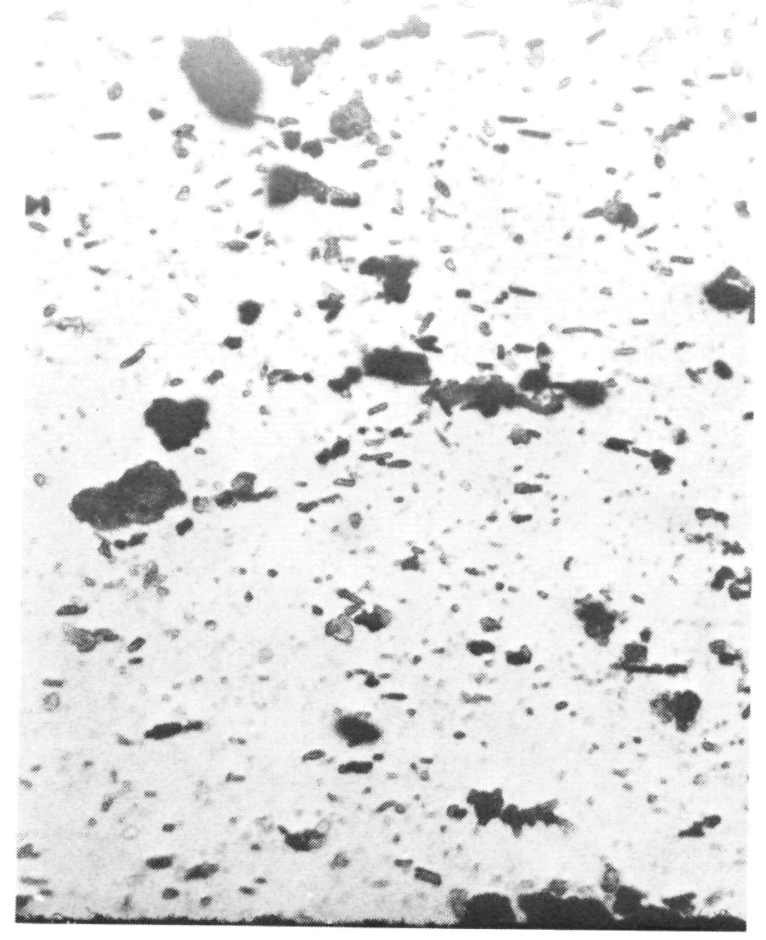

(c) $200^{\circ} \mathrm{C}$.

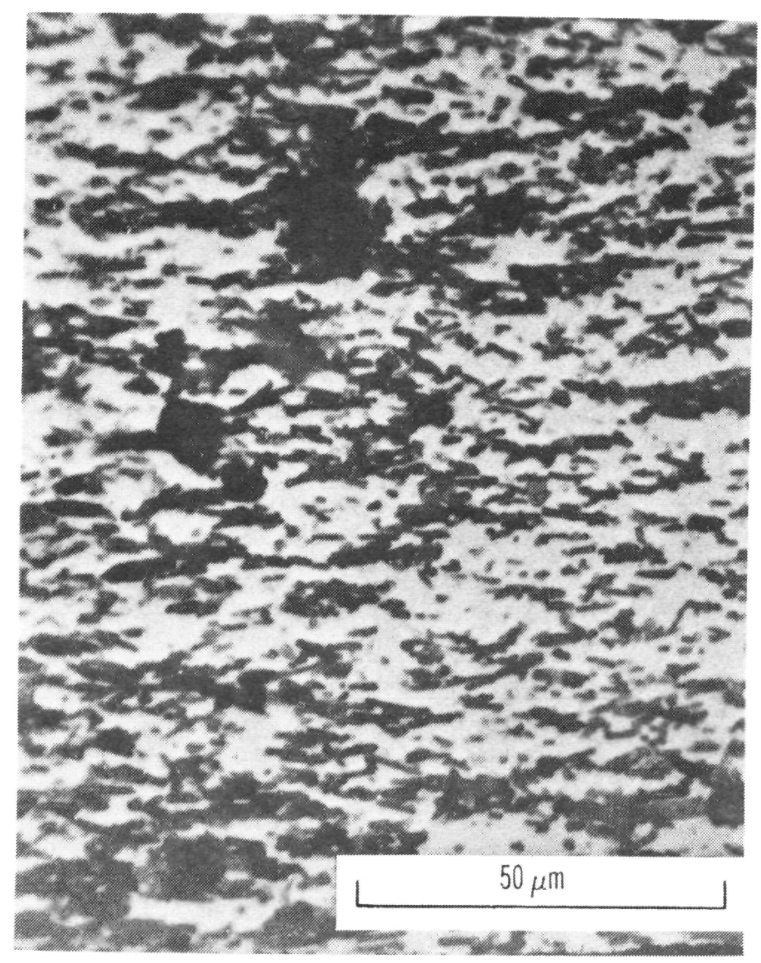

(d) $250^{\circ} \mathrm{C}$.

Figure 4. - Photomicrographs of wear debris generated by polyphenyl ether in dry nitrogen at four test temperatures. 


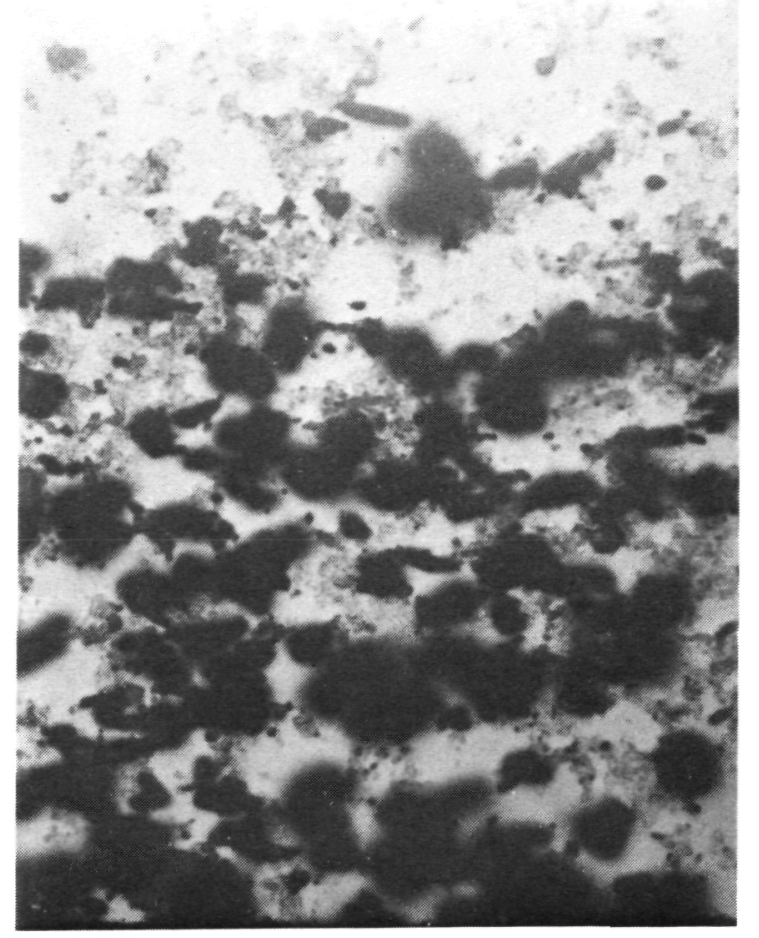

(a) Dry nitrogen.

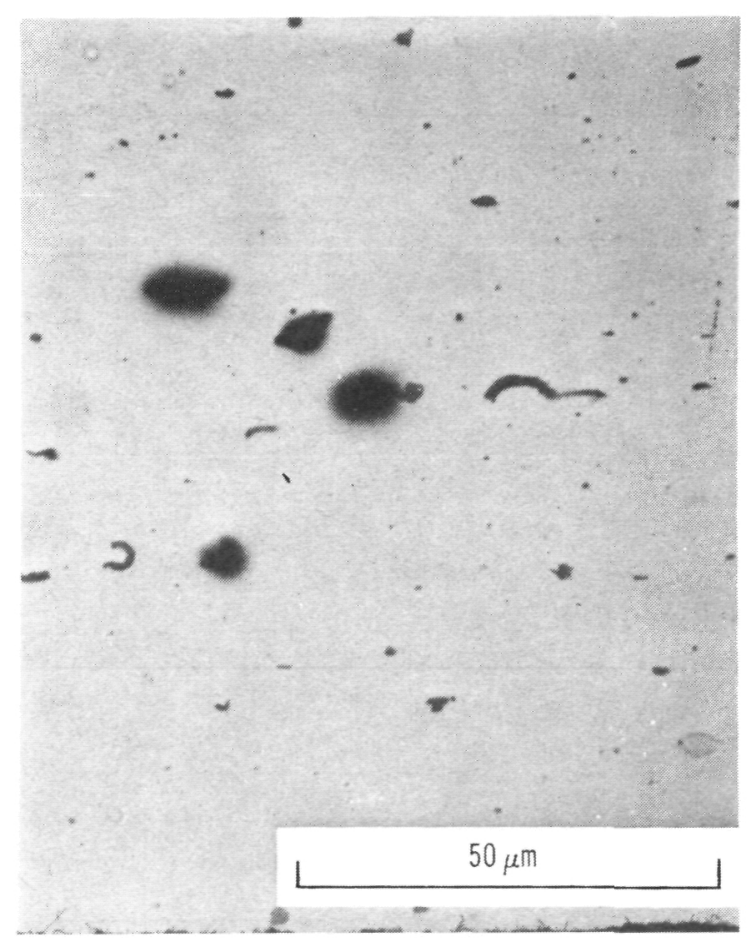

(b) Wet nitrogen (relative humidity, $>95$ percent).

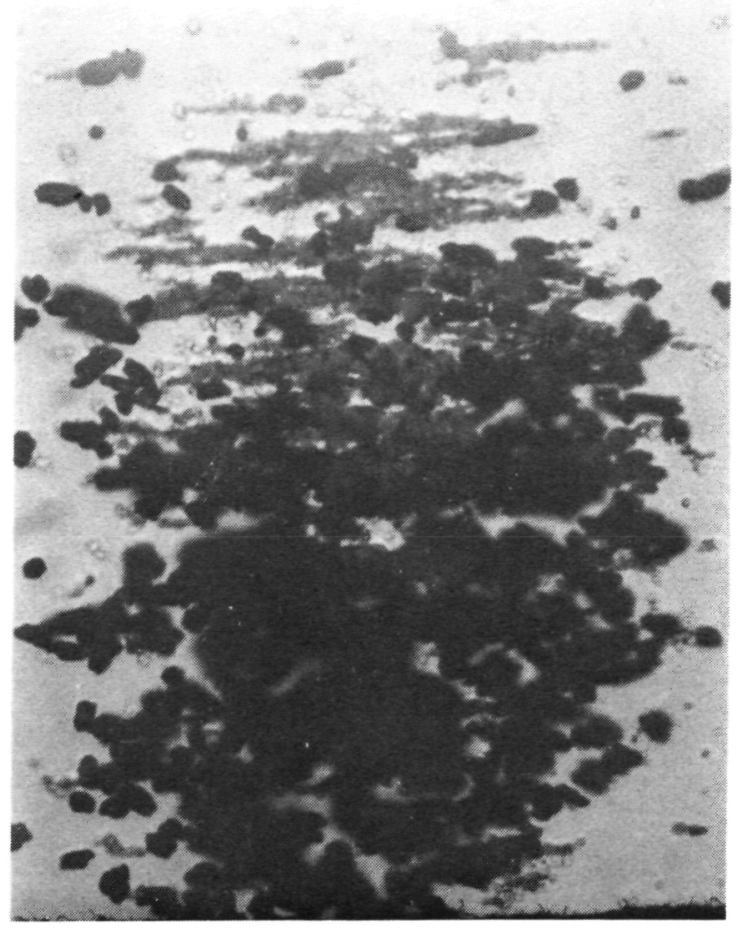

(c) Dry air.

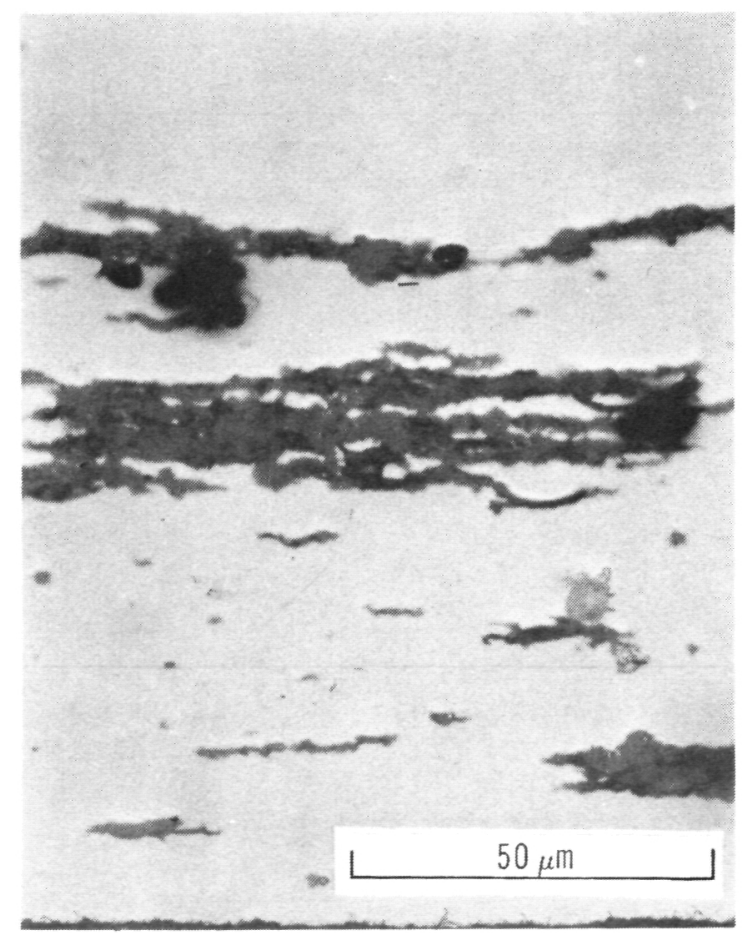

(d) Wet air (relative humidity, $>95$ percent).

Figure 5. - Photomicrographs of wear debris generated by polyphenyl ether at $100^{\circ} \mathrm{C}$ in four test atmospheres. 


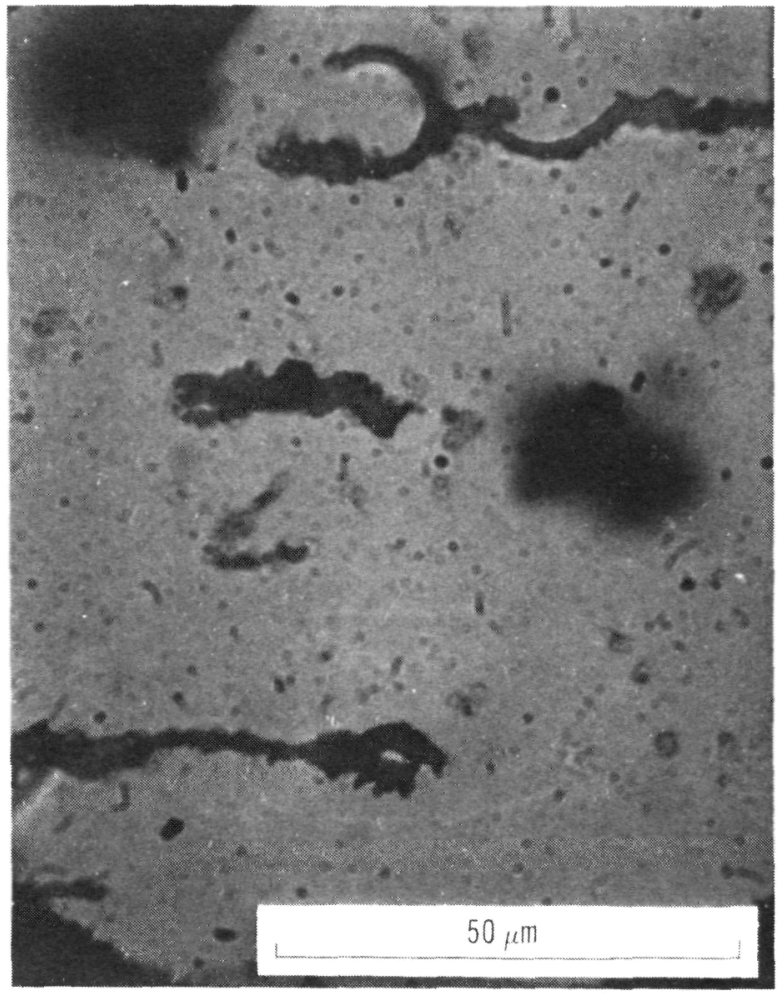

(a) Nitrogen.

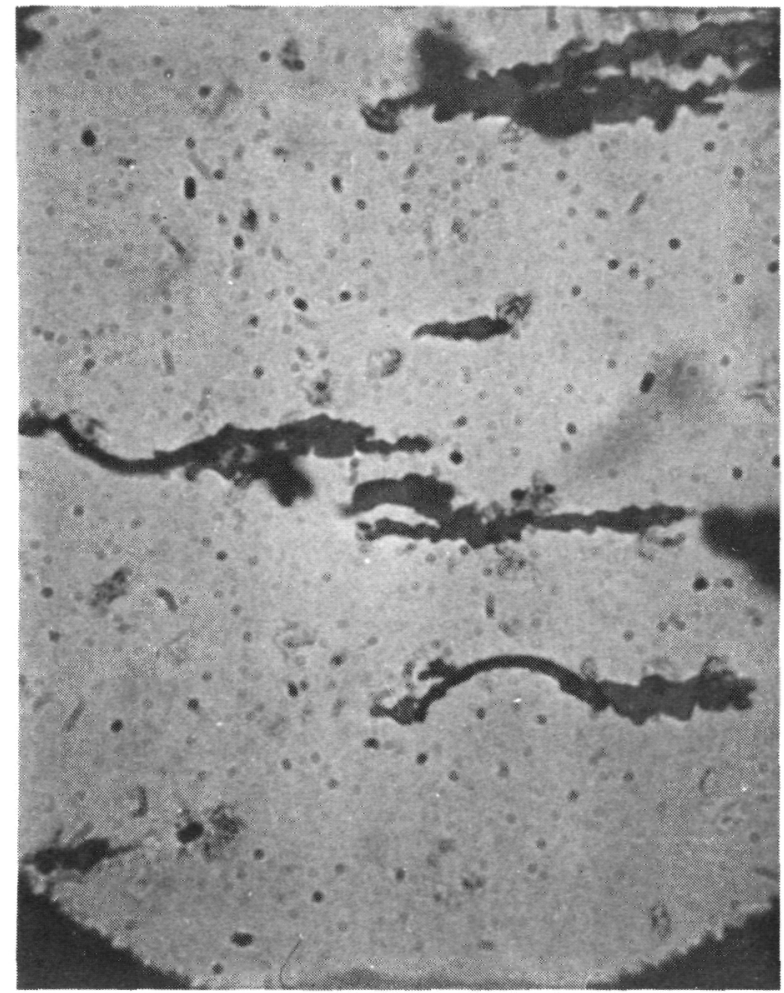

(b) Air.

Figure 6. - Photomicrographs of cutting wear debris generated by polyphenyl ether at $100^{\circ} \mathrm{C}$ in wet test atmospheres (relative humidity, $>95$ percent). 


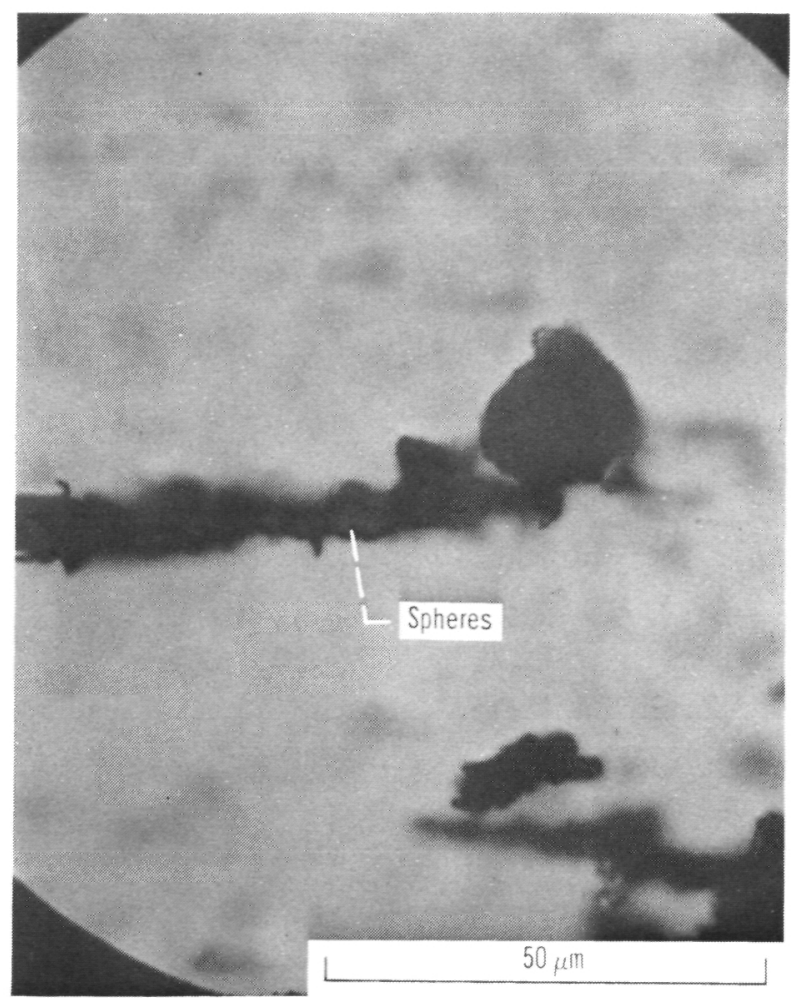

Figure 7. - Photomicrograph of wear debris containing metallic spheres generated by polyphenyl ether at $100^{\circ} \mathrm{C}$ in air (relative humidity, $>95$ percent).

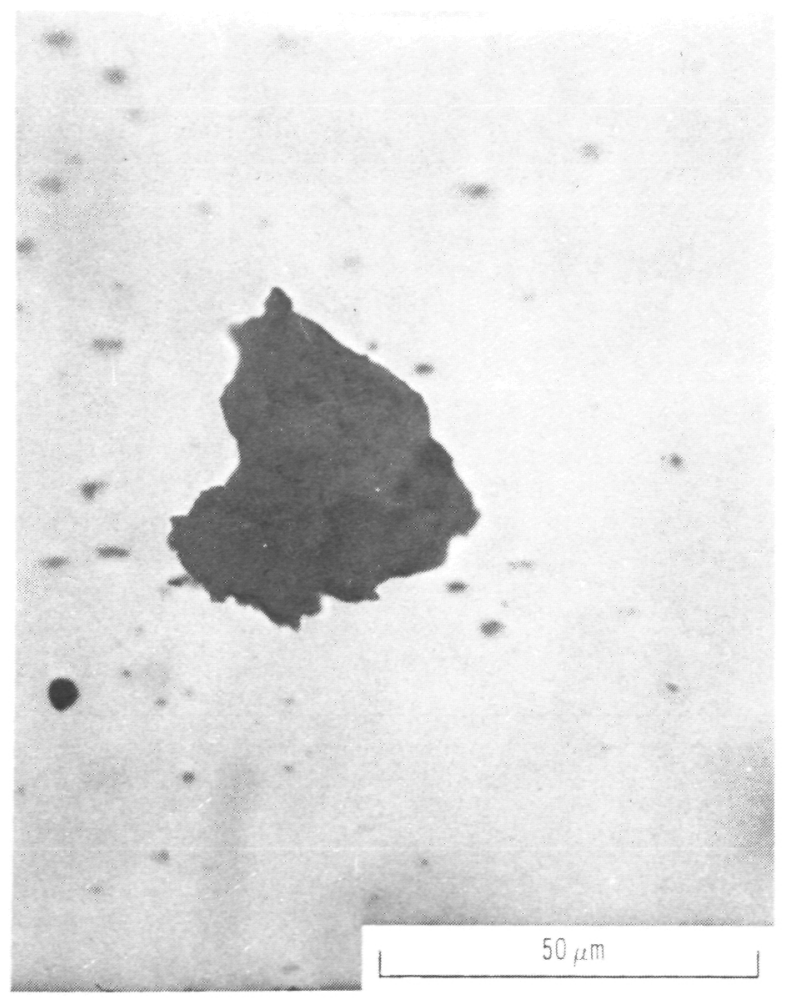

Figure 8. - Photomicrograph of large wear fragment generated by polyphenyl ether at $100^{\circ} \mathrm{C}$ in air (relative humidity, $>95$ percent). 


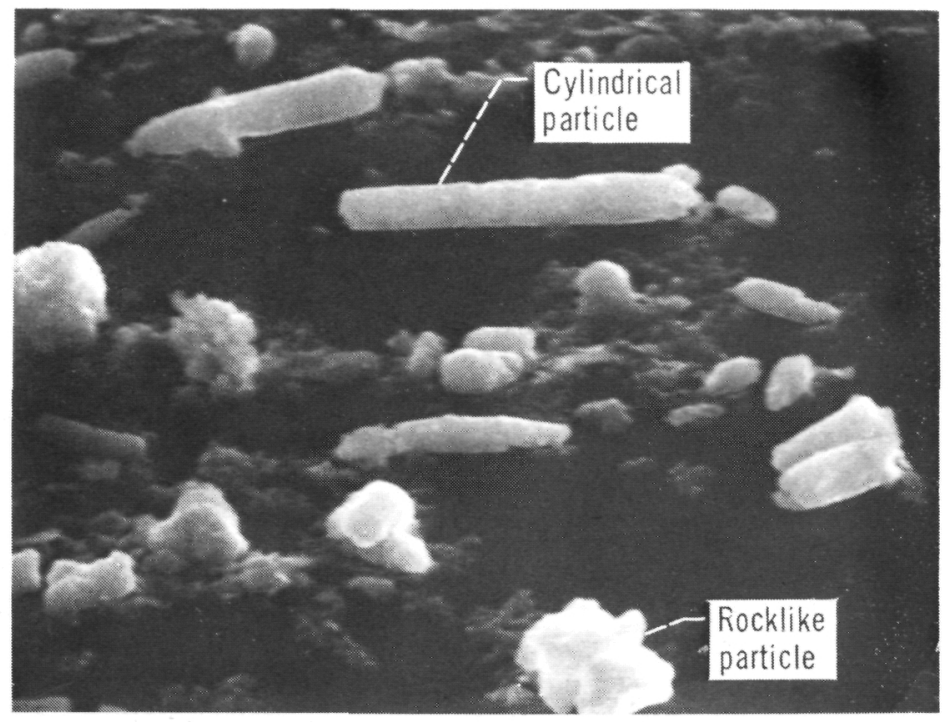

(a) Electron micrograph of carbonaceous wear debris.

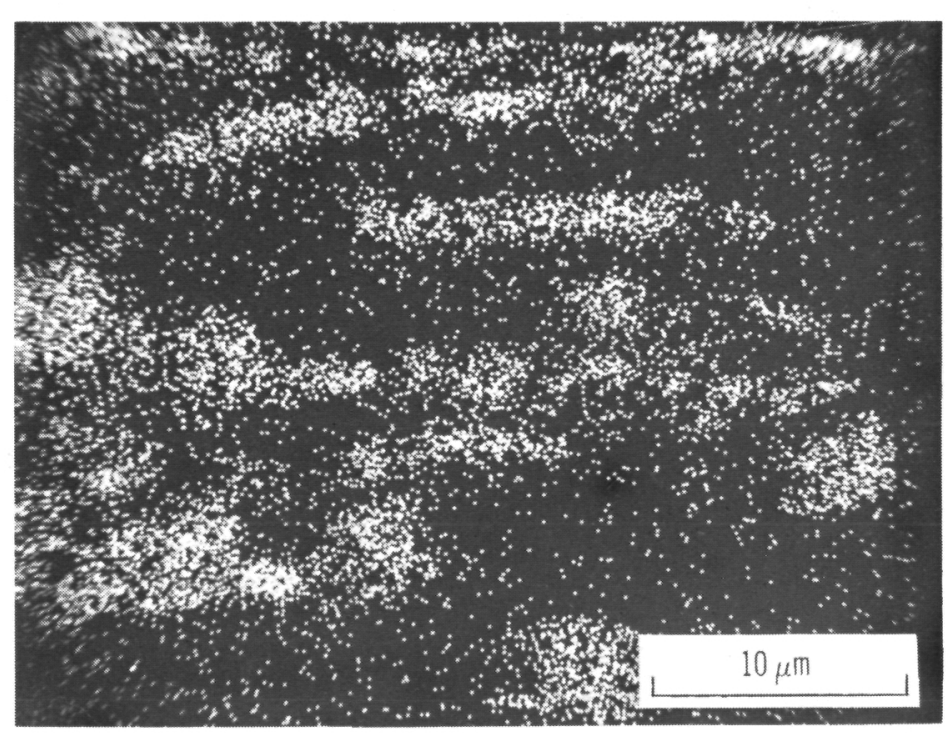

(b) Iron X-ray map.

Figure 9. - Electron micrograph of carbonaceous wear debris and iron $\mathrm{X}$-ray map of same area. 


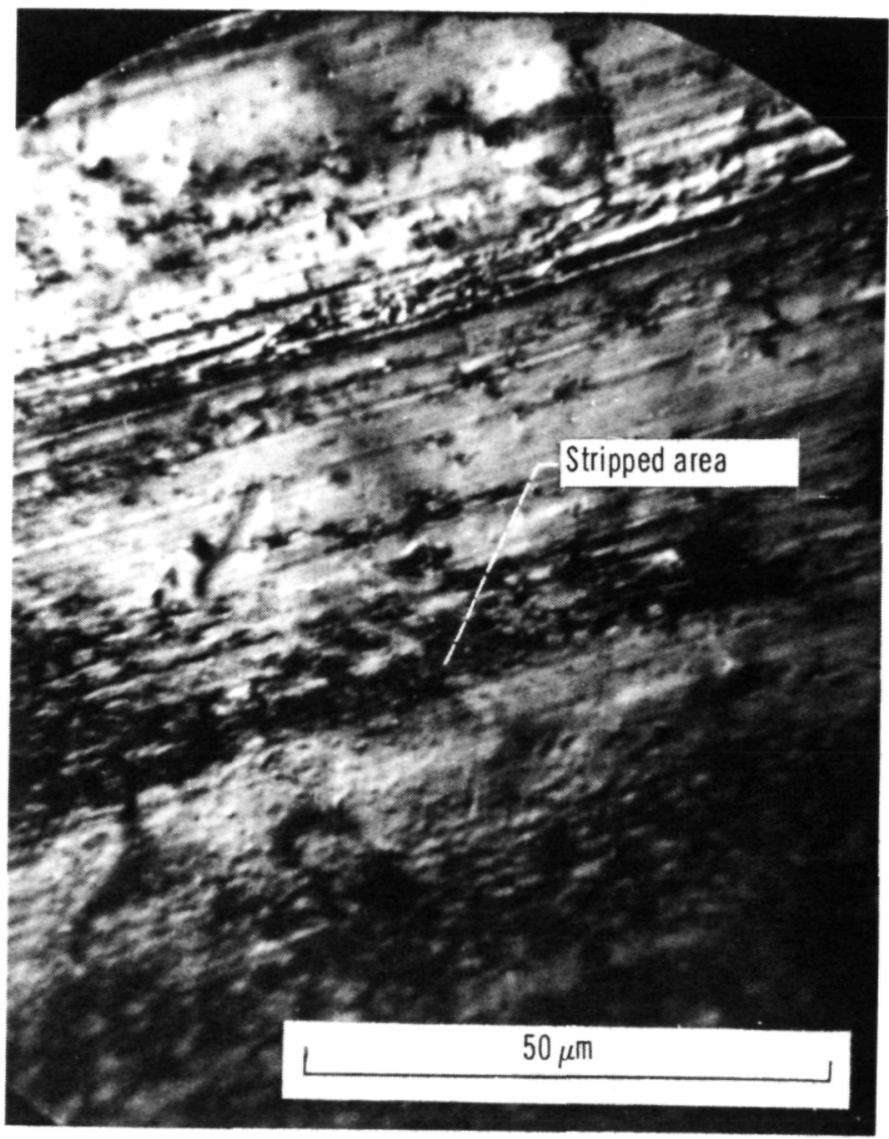

Figure 10. - Photomicrograph of wear scar obtained from interference contrast system. Lubricant, polyphenyl ether; specimen material, $\mathrm{M}-50$ steel; temperature, $100^{\circ} \mathrm{C}$; test atmosphere, nitrogen (relative humidity, 50 percent). 


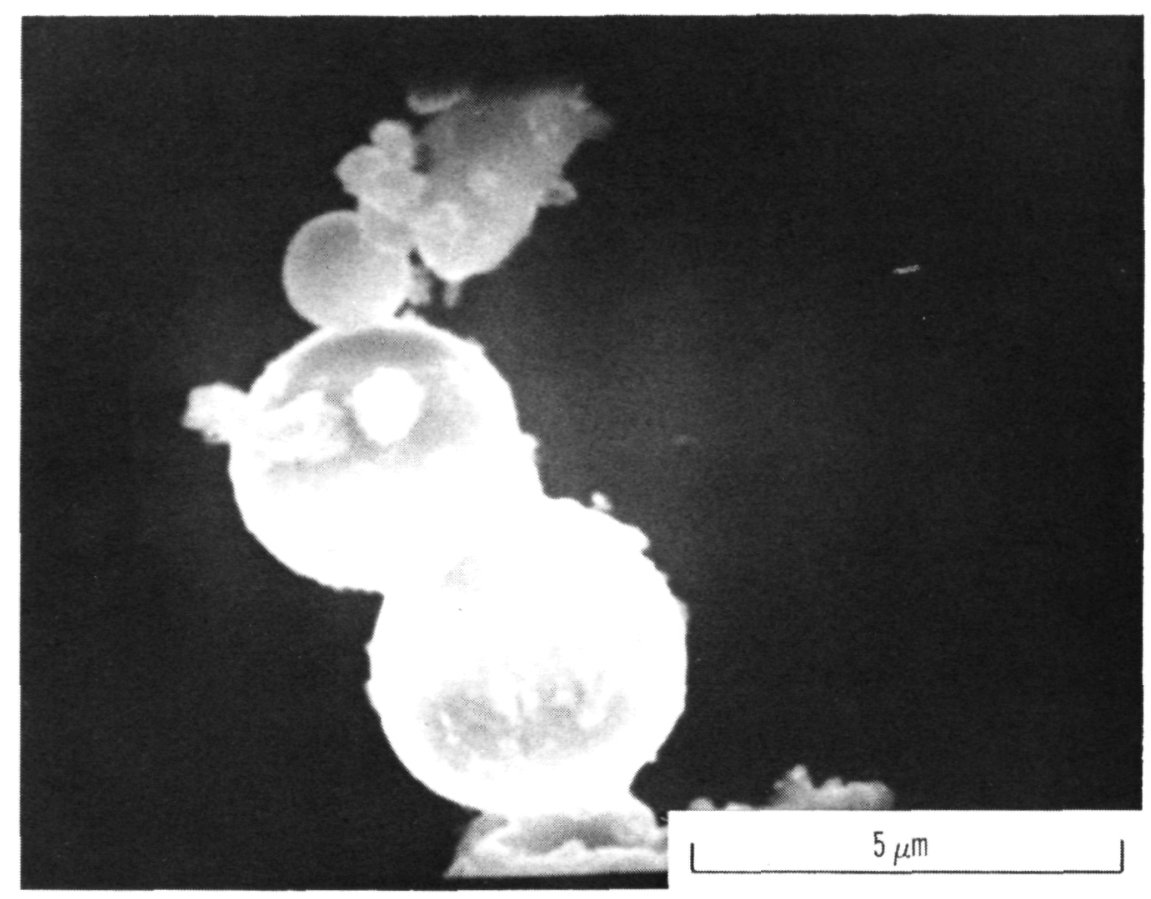

(a) Spherical particles.

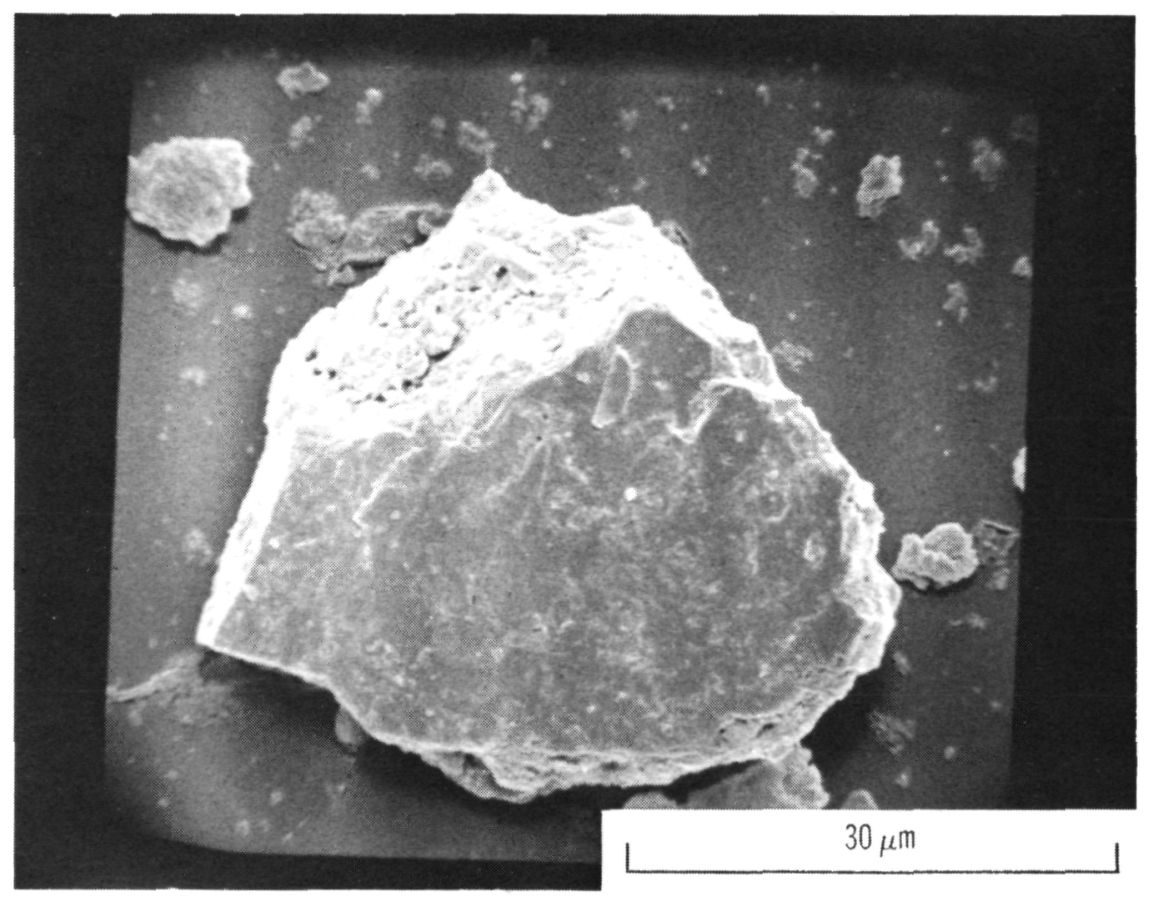

(b) Large wear fragment.

Figure 11. - Electron micrographs of two types of metallic wear debris. 
"The aeronautical and space activities of the United States shall be conducted so as to contribute ... to the expansion of buman knowledge of phenomena in the atmosphere and space. The Administration shall provide for the widest practicable and appropriate dissemination of information concerning its activities and the results thereof."

-National Aeronautics and Space ACt of 1958

\section{NASA SCIENTIFIC AND TECHNICAL PUBLICATIONS}

TECHNICAL REPORTS: Scientific and technical information considered important, complete, and a lasting contribution to existing knowledge.

TECHNICAL NOTES: Information less broad in scope but nevertheless of importance as a contribution to existing knowledge.

TECHNICAL MEMORANDUMS:

Information receiving limited distribution because of preliminary data, security classification, or other reasons. Also includes conference proceedings with either limited or unlimited distribution.

CONTRACTOR REPORTS: Scientific and technical information generated under a NASA contract or grant and considered an important contribution to existing knowledge.
TECHNICAL TRANSLATIONS: Information published in a foreign language considered to merit NASA distribution in English.

SPECIAL PUBLICATIONS: Information derived from or of value to NASA activities. Publications include final reports of major projects, monographs, data compilations, handbooks, sourcebooks, and special bibliographies.

\section{TECHNOLOGY UTILIZATION} PUBLICATIONS: Information on technology used by NASA that may be of particular interest in commercial and other non-aerospace applications. Publications include Tech Briefs, Technology Utilization Reports and Technology Surveys.

Defails on the availability of these publications may be obtained from:

SCIENTIFIC AND TECHNICAL INFORMATION OFFICE 